\title{
Multiple liver abscesses in a child ${ }^{*}$
}

\author{
Rikin K. Shah, Vinod K. Sethi, Walter J. Bridges, Abiodun O. Johnson
}

Texas Tech University Health Sciences Center, Amarillo, USA

Email: rikin.shah@ttuhsc.edu

Received 20 July 2012; revised 20 September 2012; accepted 29 October 2012

\begin{abstract}
Entameba histolytica is a protozoan that usually causes procto-colitis. E. histolytica amebiasis is endemic in tropical countries but exceedingly rare in the US Amebic liver abscess commonly presents with fever, abdominal distension, right upper quadrant pain/ tenderness, hepatomegaly, and tachycardia. We discuss the presentation/diagnosis of amebiasis in a child who had visited Mexico and the difficulty of early diagnosis when there is no evidence of intestinal infection. Ultrasonography and/or CT were essential diagnostic tools and an IgG antibody study confirmed the diagnosis. Management included oral metronidazole and abscess drainage.
\end{abstract}

Keywords: Entameba Histolytica; Ameba; Infection; Amebiasis; Abscess

\section{INTRODUCTION}

Liver abscesses are rare in children [1]. Pyogenic and amebic abscesses are most common, with amebic abscesses more prevalent in developing countries in the tropics where the protozoan, Entameba histolytica, is endemic [2]. Although E. histolytica, is found worldwide, infections are most common in lower socio-economic groups in tropical countries [3]. Travel to and immigration from such countries are the major risk factors for amebiasis in the US and other developed countries [4,5] Amebic liver abscesses are the most common extra-intestinal complication of amebic proctocolitis, and may occasionally be silent. We discuss the presentation/diagnosis of amebiasis in an 8-year old girl who had visited Mexico and the difficulty of early diagnosis when there is no evidence of intestinal infection.

\section{CASE REPORT}

A previously healthy 8-year-old girl presented with fever, abdominal pain, and nausea. Five days prior to presenta-

\footnotetext{
*Authors have no conflict of interest or funding to report.
}

tion she developed a sore throat and was diagnosed with acute pharingitis. Amoxicillin (50 mg/kg/day) was administered. There was no history of trauma, cough, chest pain, diarrhea, or emesis. The patient reported recent travel to Mexico.

On examination the patient was alert and mentally appropriate. Her temperature was $40.0^{\circ} \mathrm{C}$, pulse 126 per minute, respiration 24 per minute, and blood pressure 123/68 mm Hg. Weight was $29 \mathrm{~kg}$, length $130 \mathrm{~cm}$, and basal metabolic index 17. Neither skin rash nor lymphadenopathy was evident. The pharynx was erythematous, but without exudates and the tonsils appeared normal. She had no dyspnea, but a few rales were heard in the lower chest. The epigastric area was mildly tender without masses or hepatosplenomegaly. Scant, soft stool was evident in the rectal vault, but occult blood tests were negative. Musculoskeletal and neurological examinations were normal. Laboratory tests revealed a white blood count of $19,400 / \mathrm{mm}^{3}$ with polymorphs $81 \%$, lymphocytes $7 \%$, and monocytes $10 \%$. Clinical tests revealed hemoglobin $10.7 \mathrm{gm} / \mathrm{dL}$, hematocrit 32.1\%, red cell morphology showed mild microcytosis, and Erythrocyte Sedimenttation Rate (ESR) $78 \mathrm{~mm} / \mathrm{hr}$. Additional routine chemistries, chest and KUB x-rays were normal.

The patient was admitted and started on intravenous ceftriaxone. Fever continued for two days so azithromycin was added on day 3 . She developed diarrhea the next day with 3 - 4 loose brown stools. The epigastrium remained tender and a stool exam became positive for occult blood, but no ova, parasites, or leucocytes were seen. Computed Tomography (CT) of the abdomen and pelvis with intravenous and oral contrast showed a $6.0 \times 5.0 \mathrm{~cm}$, thickwalled liver lesion in the posterior superior right lobe and a second lesion measuring $5.6 \times 5.6 \mathrm{~cm}$ in the left lobe (Figure 1).

Due to the child's recent travel to Mexico, E. histolytica was suspected, and oral metronidazole and intravenous piperacillin/tazobactum were administered. Under sedation, ultrasound-guided needle aspiration of the abscesses produced $50 \mathrm{~mL}$ of brown fluid from each lobe. Microscopy of the aspirate revealed a fibrinopurulent exudate with scattered neutrophils and eosinophils. No organisms or trophozoites were seen, and anaerobic cul- 
ture was negative. A core biopsy was obtained from the left lobe. Histopathology showed only mild non-specific sinusoidal congestion. Serum was positive for E. histolytica IgG antibody on the day 4 (ELISA Kit, Cypress Diagnostics/Biopharma, Langdorp, Belgium). The ELISA reading was 4.0 units, and increased to 9.4 units by day 6 . Values greater than 1.2 units are considered positive; values between 0.8 - 1.9 units equivocal; and values less than 0.79 units negative. Repeated stool tests remained negative for ova, parasites, and bacteria.

By day 8, the child's temperature was normal. By day 10 her appetite was normal and she was mobile. She was discharged on oral metronidazole for an additional 14day course.

At follow-up, the child was asymptomatic and doing well. Six months after hospitalization, serum IgG antibodies to E. histolytica measured 2.6 units.

\section{DISCUSSION}

Our case report illustrates the difficulty with early diagnosis of amebic liver abscess when there is no preceding intestinal infection. Amebic liver abscess commonly presents with fever, abdominal distension, right upper quadrant pain/tenderness, hepatomegaly, and tachycardia.
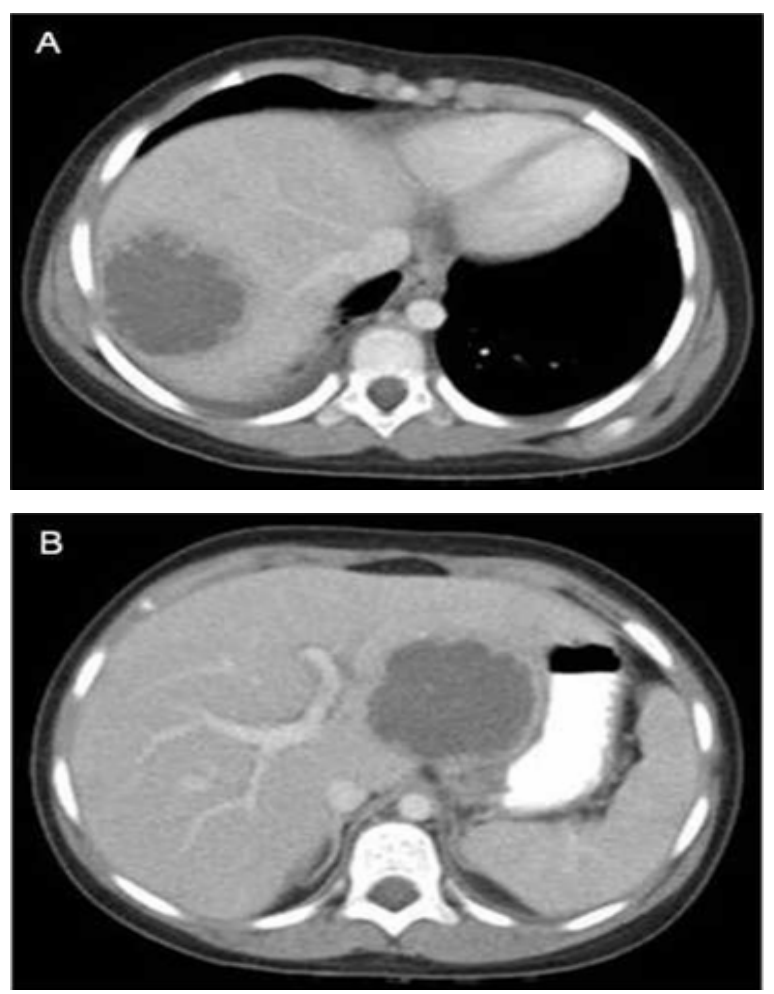

Figure 1. (A) Computed tomography (CT) of the abdomen and pelvis with intravenous and oral contrast showed a $6.0 \times$ $5.0 \mathrm{~cm}$, thick-walled liver lesion in the posterior superior right lobe and (B) a second lesion measuring $5.6 \times 5.6 \mathrm{~cm}$ in the left lobe.
Our patient had fever and epigastric tenderness, but no hepatomegaly or liver tenderness. Table 1 compares clinical presentation of our patient with previous similar publications [6-9].

Patients with amebic liver abscess do have leucocytosis with an average white blood cell count of 16,000 on initial presentation [10]. Our patient's rales, fever, leucocytosis with left shift (81\% polymorphs), and elevated ESR suggested pneumonia, but the chest $\mathrm{x}$-ray was negative. Loose stools, positive for occult blood, the CT images of abscesses, and knowledge of the Mexico travel in our patient prompted piperacillin/tazobactum treatment. Serology for amebic infection was obtained and metronidazole was added. The E. histolytica IgG antibody study, obtained later, could not distinguish previous from current infection, but our patient's response to treatment suggested current infection.

The ELISA kits for the serodiagnosis of E. histolytica are positive in approximately $95 \%$ of patients with extra-intestinal amebiasis, about $70 \%$ with intestinal infection, and in $10 \%$ of asymptomatic carriers passing cysts [11]. The IgG-ELISA has sensitivity of 99\% and specificity of $91.7 \%$, is the preferred test. While IgM-ELISA has sensitivity of $64 \%$, is not used as an index of active amoebic infection [12].

Appropriate anti-microbial or anti-parasitic agents and abscess drainage are essential for clinical management. Ultrasonography and/or CT help define the size and location of each abscess [13]. Ultrasound-guided percutaneous needle aspiration is the preferred mode of liver abscess drainage, especially when diameters are $5 \mathrm{~cm}$ or less [14].

About $90 \%$ of the cases of E. histolytica are asymptomatic. The others develop diarrhea, dysentery (proctocolitis), and/or abscesses (liver, spleen, and/or brain). Complications include rupture, gastric perforation, and Budd-Chiari syndrome $[15,16]$. Significant morbidity and mortality may occur, especially if the nature of the primary infection is not appreciated in good time. An estimated 100,000 deaths result each year from E. histolytica infection, primarily in endemic areas. A high index

Table 1. Clinical features in pediatrics amebic liver abscess.

\begin{tabular}{cccccc}
\hline & $\begin{array}{c}\text { Guittet } \text { et } \\
\text { al. } \mathrm{n}=10\end{array}$ & $\begin{array}{c}\text { Marten et } \\
\text { al. n= }\end{array}$ & $\begin{array}{c}\text { Nazir et al. } \\
\mathrm{n}=24\end{array}$ & $\begin{array}{c}\text { Haffar et al. } \\
\mathrm{n}=124\end{array}$ & $\begin{array}{c}\text { Our } \\
\text { patient }\end{array}$ \\
\hline Fever & $100 \%$ & $>99 \%$ & $100 \%$ & $100 \%$ & + \\
Abd. Pain & $60 \%$ & $94 \%$ & $91.2 \%$ & $91 \%$ & + \\
Diarrhea & $20 \%$ & $54 \%$ & $\mathrm{NM}$ & $76 \%$ & - \\
Vomiting & $30 \%$ & $\mathrm{NM}$ & $29 \%$ & $31 \%$ & - \\
Hepatomegaly & $40 \%$ & $92 \%$ & $100 \%$ & $81 \%$ & - \\
\hline
\end{tabular}

$\mathrm{N}=$ number of patients; Abd. = abdominal; $\mathrm{NM}=$ not mentioned. 
of suspicion in the care of a patient with an unusual clinical course who has traveled to an endemic area is necessary for early diagnosis.

\section{REFERENCES}

[1] Muorah, M., Hinds, R. and Verma, A. (2006) Liver abscesses in children: A single center experience in the developed world. Journal of Pediatric Gastroenterology and Nutrition, 42, 201-206. doi:10.1097/01.mpg.0000189344.23387.26

[2] Kurland, J.E. and Brann, O.S. (2004) Pyogenic and amebic liver abscesses. Current Gastroenterology Reports, 6, 273-279. doi:10.1007/s11894-004-0078-2

[3] Rehman, A.A., Rizvi, F. and Kazim, S.F. (2010) Amoebic liver abscess: Experience in a south Asian country. Tropical Doctor, 40, 39-40. doi:10.1258/td.2009.090089

[4] Giorgio, A., Esposito, V. and Farella, N. (2009) Amebic liver abscesses: A new epidemiological trend in a nonendemic area. In Vivo, 23, 1027-1030.

[5] Pickering, L.K. and Kimberlin, D.W. (2009) Amebiasis. In: Pickering, L.K. and Kimberlin, D.W., Eds., Red Book: 2009 Report of Committee on Infectious Diseases. Elk Grove Village, American Academy of Pediatrics, 206208.

[6] Guittet, V., Ménager, C., Missotte, I., Duparc, B., Verhaegen, F. and Duhamel, J.F. (2004) Hepatic abscesses in childhood: Retrospective study about 33 cases observed in New-Caledonia between 1985 and 2003. Archives of Pediatrics \& Adolescent Medicine, 11, 1046-1053.

[7] Merten, D.F. and Kirks, D.R. (1984) Amebic liver abscess in children: The role of diagnostic imaging. American Journal of Roentgenology, 143, 1325-1329.

[8] Nazir, Z. and Moazam, F. (1993) Amebic liver abscess in children. The Pediatric Infectious Disease Journal, 12 929-932. doi:10.1097/00006454-199311000-00008

[9] Haffar, A., Boland, F.J. and Edwards, M.S. (1982) Amebic liver abscess in children. The Pediatric Infectious Disease Journal, 1, 322-327. doi:10.1097/00006454-198209000-00008

[10] Hughes, M.A. and Petri, W.A. (2000) Amebic liver abscess. Infectious Disease Clinics of North America, 14, 565-582. doi:10.1016/S0891-5520(05)70121-5

[11] Singh, A., Houpt, E. and Petri, W.A. (2009) Rapid diagnosis of intestinal parasitic protozoa, with a focus on Entamoeba histolytica. Interdisciplinary Perspectives on Infectious Diseases, 2009, 8. doi:10.1155/2009/547090

[12] Sathar, M.A., Simjee, A.E., Nel, J.D., Bredenkamp, B.L., Gathiram, V. and Jackson, T.F. (1988) Evaluation of an enzyme-linked immunosorbent assay in the serodiagnosis of amoebic liver abscess. South African Medical Journal, 74, 625-628.

[13] Merten, D.F. and Kirks, D.R. (1984) Amebic liver abscess in children: The role of diagnostic imaging. American Journal of Roentgenology, 143, 1325-1329.

[14] Zerem, E. and Hadzic, A. (2007) Sonographically guided percutaneous catheter drainage versus needle aspiration in the management of pyogenic liver abscess. American Journal of Roentgenology, 189, 138-142. doi:10.2214/AJR.07.2173

[15] Mechai, F., Aoun, O., Ficko, C., Barruet, R., Imbert, P. and Rapp, C. (2009) Budd-Chiari syndrome as a vascular complication of amebic liver abscess. The American Journal of Tropical Medicine and Hygiene, 81, 768-769. doi:10.4269/ajtmh.2009.09-0230

[16] Rao, S., Solaymani-Mohammadi, S., Petri, W.A. and Parker, S.K. (2009) Hepatic amebiasis: A reminder of the complications. Current Opinion in Pediatrics, 21, 145149. doi:10.1097/MOP.0b013e32831ef249 